\title{
Best Practices in Preconstruction Services for Transportation Projects
}

\author{
Evan Bingham ${ }^{1 *}$, G. Edward Gibson, Jr. ${ }^{2}$, and Mounir El Asmar ${ }^{3}$
}

\begin{abstract}
Preconstruction refers to project planning and services performed before construction takes place. It is a critical phase in the development of civil infrastructure projects. Civil infrastructure projects such as highways, freeways and other transportation related projects rely heavily on the preconstruction phase to improve partnerships, increase inter/intra-firm coordination and collaboration, and ensure a higher probability of successful project outcomes. Preconstruction services vary by project delivery method in terms of cost, timing, and level of benefit received. When a practice reaches a level of great value to the industry, it is often referred to as a 'best practice"'. This paper discusses the delivery method and industry best practices that are most beneficial for successfully implement preconstruction services Results of a recent study using data gathered from 81 U.S. project owners, referencing projects from 17 states, and totaling over 6 billion U.S. dollars are given. The study identifies and ranks the best practices for performance of preconstruction services within each delivery method. Moreover, the paper presents an analysis of variance identifying the preconstruction services that add the most value to a given project, as well as the best practices to implement in order to effectively deliver a specific preconstruction service. Additionally, a cost analysis of project data is presented to identify average costs for preconstruction services. Guidance from industry leaders is presented to improve team alignment, partnering, firm coordination, and overall project success.
\end{abstract}

\section{Keywords}

Preconstruction, Best Practices, Delivery Method

\footnotetext{
${ }^{1}$ Assistant Professor, Construction and Facilities Management, Ira A. Fulton College of Engineering and Technology, Brigham Young University, Provo UT, 84602, Evan.Bingham@byu.edu (corresponding author)

2 Director, School of Sustainable Engineering and the Built Environment, Professor and Sunstate Chair of Construction Management and Engineering, Arizona State University, P.O. Box 873005 Tempe AZ, 85287-3005, 480-965-7972, Fax 480-9651769, Edd.Gibson@asu.edu

3 Assistant Professor, School of Sustainable Engineering and the Built Environment, Arizona State University, P.O. Box 873005 Tempe AZ, 85287-3005, 480-727-9023, asmar@asu.edu
}

The Engineering Project Organization Journal (C)2017 Engineering Project Organization Society www.epossociety.org 
for owners to have as much current information as

\section{Introduction}

Motivation for the study reported here was based on the request of a large group of owners and contractors to answer the question of how to improve the services performed in the preconstruction phase of a project. A select group from the Alliance for Construction Excellence (ACE), an organization focused on training industry leaders, funded and guided the research. Specific research goals included: providing a list of the most common preconstruction services used in the industry, determining the best delivery methods for performing preconstruction services, discovering average costs for preconstruction services by delivery method, identifying and providing definitions of practices termed 'best practices' by the industry, and compiling a matrix of preconstruction services and the best practices to accomplish these services.

This paper constitutes a summary of findings from a large collection of project data and project owner surveys, which identify the industry's best practices in performing preconstruction services. Additionally, the paper examines the effectiveness of different delivery methods in performing preconstruction services. Typical costs for these services for transportation projects are also reported. The purpose of the paper is to improve the performance of transportation infrastructure projects.

Preconstruction is one of the most important keys to project success (Gidado 2004). Preconstruction services are performed as a part of project delivery to facilitate design, construction, and operation phases. With the implementation of alternative project delivery methods (APDM) such as designbuild and construction manager at risk, which allow for earlier involvement from contractors, the ability to perform preconstruction services has improved (Farnsworth 2015). The preconstruction phase often stands alone as a measurable deliverable to a project owner. As companies seek to improve the way they perform preconstruction services, it is important to understand the best practices to implement to meet the organization's goals for a project. With the increase of use of technologies like BIM it also becomes important possible to make important business decisions (Karan 2015). Additionally, understanding the cost implications of preconstruction services is important to all parties. This paper identifies and defines the preconstruction services being performed by transportation contractors, presents project data providing average costs associated with these services, and provides input from industry leaders with regard to the best practices that should be used in performing preconstruction services.

\section{Background}

Preconstruction is the name given to the phase of the project prior to actual construction. There are many services that can be performed by a contractor to facilitate a smoother, more successful construction process. These services depend on several important factors, including the contract relationships, project delivery method, and project size and complexity. One objective of this research is to better understand how agencies might better perform preconstruction services. Part of the survey was dedicated to the discovery of the management practices used in the preconstruction phases and how these led to success. Twenty-one preconstruction services were identified they include:

- Identification of project objectives

- Risk identification and assessment

- Risk mitigation

- Design management

- Agency coordination and estimating

- Constructability/bidability analysis

- Value analysis/engineering

- Bid packaging

- Schedule development

- Site logistics planning

- Disruption avoidance planning

- Small, women, and minority owned business enterprise participation

- Construction phase sequencing

- Subcontractor prequalification

- Multiple bid package planning

- Real-time cost feedback 
- Building information modeling

- Total cost of ownership analysis

- Cost estimating

- Budget management

- Stakeholder management

Industry professionals have sought to identify practices that have the greatest ability to improve a project. When a method or tool is widely used or has proved valuable it is considered a best practice. The Construction Industry Institute (CII) is one organization that has identified some of these best practices. Because an understanding of the definition of each practices will improve understanding of the related research that follows hereafter, a definition of each is given. These definitions were adapted to better fit the narrower subject matter of this research.

Best Practice Definitions: Adapted from the CII glossary (CII 2014)

Alignment: The condition where appropriate project participants are working within acceptable tolerances to develop and meet a uniformly defined and understood set of project objectives.

Benchmarking \& Metrics: The systematic process of measuring an organization's performance against recognized leaders for the purpose of determining best practices that lead to superior performance when adapted and utilized.

Change Management: The process of incorporating a balanced change culture of recognition, planning, and evaluation of project changes in an organization to effectively manage project changes.

Constructability: The effective and timely integration of construction knowledge into the conceptual planning, design, construction, and field operations of a project to achieve the overall project objectives in the best possible time and accuracy at the most cost-effective levels.

Disputes Prevention \& Resolution: Techniques that include the use of a Disputes Review Board as an alternate dispute resolution process for addressing disputes in their early stages before affecting the progress of the work, creating adversarial positions, and leading to litigation.

Front End Planning: The essential process of developing sufficient strategic information with which owners can address risk and make decisions to commit resources in order to maximize the potential for a successful project.

Lessons Learned: A critical element in the management of institutional knowledge, an effective lessons learned program will facilitate the continuous improvement of processes and procedures and provide a direct advantage in an increasingly competitive industry.

Materials Management: An integrated process for planning and controlling all necessary efforts to make certain that the quality and quantity of materials and equipment are appropriately specified in a timely manner, are obtained at a reasonable cost, and are available when needed.

Partnering: A long-term commitment between two or more organizations as in an alliance or it may be applied to a shorter period of time such as the duration of a project. The purpose of partnering is to achieve specific business objectives by maximizing the effectiveness of each participant's resources.

Planning for Startup: Startup is defined as the transitional phase between construction completion and operations, it encompasses all activities that bridge these two phases, including turnover, check-out of systems, and performance testing.

Project Risk Assessment: The process to identify, assess, and manage risk. The project team evaluates risk exposure for potential project impact to provide focus for mitigation strategies.

Quality Management: Quality management incorporates all activities conducted to improve the efficiency, contract compliance and cost effectiveness of design, engineering, procurement, QA/QC, construction, and startup elements of construction projects.

Team Building: A project-focused process that builds and develops shared goals, interdependence, trust and commitment, and accountability among team members and that seeks to improve team members' problem-solving skills.

Zero Accidents Techniques: Include the sitespecific safety programs and implementation, auditing, and incentive efforts to create a project environment and a level of training that embraces the mind-set that all accidents are preventable and that zero accidents is an obtainable goal.

Sustainable Construction: Addresses the triple bottom line - the social, economic and 
environmental performance of the industry; delivering buildings and structures that provide greater satisfaction, well-being and added value to customers and users; respecting community, improving health and safety, enhancing site and welfare conditions, enhancing and protecting the natural environment, minimizing consumption of natural resources and energy throughout the life of the facility.

Value Engineering: A systematic process of review and analysis of a project, during the concept and design phases to provide recommendations for needed functions safely, reliably, efficiently, and at the lowest overall cost, improving the value and quality of the project; and reducing the time to complete the project.

Life Cycle Costing: Method used to measure the costs of ownership of a building. It takes into account the initial capital, cost of maintaining and servicing the building over its whole life.

\section{Literature Review}

The literature reviewed in this effort fits into two categories. Because this work is a cross analysis of industry best practices and preconstruction services, existing research into these two topics was the main focus of the review. In addition to these individual topics the authors searched for literature that performed similar analyses of best practices and preconstruction services together. The literature review summarized hereafter gives a brief description of the most relevant findings as well as support for the pursuit of further research in these areas. A literature review found that multiple research efforts identified a lack of analysis of preconstruction practices, especially with regard to the different delivery methods (FHWA 2006). Recent studies have been conducted with the purpose of identifying average costs for preconstruction services. A study by the Utah Department of Transportation found that the average fee for preconstruction services on highway projects was 0.80 percent of estimated construction costs (UDOT 2010). However, an analysis of preconstruction service costs by delivery type was not performed, and only a small sample size of ten projects was used. This paper reports a much larger sample size (81), improving the analysis of preconstruction costs. More recently The Transportation Research Board has performed research addressing the principle sources and components of PCS costs (NCHRP 2016). Anecdotal reports as well as individual case studies are the most prevalent form of literature in the area of preconstruction services. One notable article dealing with best practices for preconstruction services was published in 2007 in the Construction Business Owner (Kuhn 2007). This article was helpful in defining preconstruction, and how it can be used to improve a project. In the article, a graph of delivery methods describes the amount of involvement for contractors in the phases of construction. Preconstruction involvement is greatest for Design Build projects with contractor involvement through the planning, schematics, design development, construction documents, bid, and construction phases. Construction Manager at Risk is involved starting with a schematic document phase, and finally, Design Bid Build only performs preconstruction services during the bid period (Kuhn 2007). In terms of best practices during the preconstruction phase, advice was given regarding the decisions made on documents, ways to deal with variance reports, and managing the bid list. Although the article is helpful in understanding more about preconstruction services, like most works on the topic, data representing a good statistical representation of owners did not exist. More research is needed to understand the trends of the industry and the most current best practices. This paper contributes to the body of knowledge by reporting results from a large sample of industry professionals who have identified the best practices to successfully provide preconstruction services. The primary motivation for the study being reported here was the lack of in depth analysis of the practices that should be used for effective implementation of preconstruction services.

\section{Methodology: Hypotheses and Method of Analysis}

The preconstruction service phase of a project has been shown to have a great effect on project outcomes. It is arguably the most important phase in the construction process to ensure successful 
project outcomes and has direct correlation with project success (CII 1994). It is, therefore, important to determine the most effective ways for practitioners to perform the tasks associated with this critical phase. To study the practices best fit to accomplish a preconstruction service and to additionally determine the delivery method that could most easily facilitate each service, a survey of 81 project owners was performed. The resulting data was used to test the following hypotheses:

Null hypothesis $\mathrm{H}_{0}: \mu=\mu_{0}$ - There is not a correlation between individual preconstruction services and delivery method.

Alternate hypothesis $\mathrm{H}_{\mathrm{A}}: \mu \neq \mu_{0}$ - Individual preconstruction services have a correlation with delivery method. Specific delivery methods will have a greater ability to influence the use of a specific preconstruction service.

Additional hypothesis tested:

Null hypothesis $\mathrm{H}_{0}: \mu=\mu_{0}-$ There is not a correlation between individual preconstruction services and industry best practices.

Alternate hypothesis $\mathrm{H}_{\mathrm{A}}: \mu<\mu_{0}-$ Individual preconstruction services have a correlation with industry best practices. Specific best practices will have a greater ability to influence the use of a specific preconstruction service.

The first step for analysis of research hypotheses, was the collection of general practice and project specific data. A survey was conducted for transportation projects. The survey was developed and tested by an advisory council from the Alliance for Construction Excellence (ACE). ACE is a group focused on training industry leaders, they also fund research as it fits their educational goals. The team was comprised of over a dozen owner and constructors representing the transportation infrastructure sector. The advisory group developed survey questions to address topics determined most valuable to industry leaders. Survey data was collected by soliciting responses via email from national and state department of transportation offices, as well as municipalities, managers of transportation projects, and FHWA listed SEP 14 projects. Of the 105 survey respondents, 81 were considered to have usable data. The other 22 responses were deemed unusable due to various reasons such as insufficient data, inadequate project size, or data not relevant to the study. Projects were located across the continental U.S. and Alaska. The project locations and number of projects are provided below:

$\begin{array}{lll}\text { Alaska }-9 & \text { Georgia }-9 & \text { Montana }-1 \\ \text { Arizona }-13 & \text { Idaho }-6 & \text { Tennessee }-4 \\ \text { California }-3 & \text { Louisiana }-2 & \text { Utah }-9 \\ \text { Colorado }-1 & \text { Maryland }-8 & \text { DC }-1 \\ \text { Delaware }-2 & \text { Michigan }-1 & \text { Wyoming }-4 \\ \text { Florida }-7 & \text { Minnesota }-1 & \text { Total }-81\end{array}$

The survey collected project outcome data as well as a history of practices used for each project. These practices were tied to actual project outcomes, as well as the owner's perception of project outcomes or factors leading to project successes and failures. All projects included in the study were horizontal projects dealing with the transportation of people and/or freight. Projects used in the study fell mostly into three categories: Design Build (DB), Design Bid Build (DBB), and Construction Manager at Risk (CMAR). Design Bid Build was the dominant project delivery method, with 40 of the projects in the study using this delivery method. Design Build was used on 21 projects in the study. This was followed by 19 CMAR projects. Other projects in the study used different delivery methods, such as Job Order Contracting (JOC), not covered in detail in this paper. The 81 survey participants reported on individual projects on which they had a management or ownership role. The projects ranged in cost from one million to over 900 million US dollars. They represent a total capital project value of almost six billion US dollars. DBB projects had the lowest average cost at just over 19 million US dollars. CMAR projects had an average cost of over 22 million US dollars, and DB projects had the highest average cost at just over 51 million US dollars. DB projects also showed the largest range of project costs.

Consultation from design and owner representatives was received from over 40 organizations that reported on the preconstruction services that had been performed for their 
organizations. This information was then used to create the list of preconstruction services used in the national survey.

Data collection resulted in the analysis of data using multiple statistical tools. Analysis of means, analysis of variance, and other statistical tests were used to determine the statistical significance of the observed differences. The primary method of analysis to validate research hypotheses was comparison of means and an analysis of variance within the data sets. Collected data was tested for normal distribution. Results for skewness and kurtosis tests showed that collected data had a standard normal distribution; therefore, no adjustments to survey data were necessary for the samples used for hypothesis testing. Survey data provided a useful, simple and accurate approximation and representation of the population represented. This finding is supported through the central limit theorem providing for analysis of data with a standard normal distribution (Hayter 2002). The first set of hypotheses being tested were considered to be a two sided hypothesis test, in other words $\mathrm{H}_{0}: \mu=\mu_{0}$ versus $\mathrm{H}_{0}: \mu \neq \mu_{0}$. A two sided t-test was used to determine if there was any difference from the mean of the population and the group in question. A 95 percent confidence interval was used to determine if there was a significant variation between the means of the data sets. This would imply that the results of data would need a p-value greater than 0.05 to be significant at the 95 percent confidence interval. Because there are multiple means that were compared, means that showed significant variance $(p>0.05)$ have been shown with an asterisk in the results portion of this paper.

The second set of hypotheses were tested using a one sided t-test where the mean of the subsample was compared to the mean of the whole sample to determine if its value was greater than the whole sample mean. $\mathrm{H}_{\mathrm{A}}: \mu=\mu_{0}$ versus $\mathrm{H}_{\mathrm{A}}: \mu<\mu_{0}$. Once again this analysis was repeated over 20 times, once for each parameter, and analysis reaching a statistically significant level was noted with the color green.

\section{Results and Discussion}

This section provides the results of the testing of research hypotheses. In addition to this, useful information obtained through the survey is also provided. These are results that were not tested using statistical analysis but give important information that can be used to understand the population being tested.

The survey identifies preconstruction activities widely used in the industry. These services are then categorized and analyzed by delivery method. Preconstruction costs are then discussed, and finally, the use of best practices in accomplishing preconstruction goals is reported.

\section{Preconstruction Elements and Delivery Method}

The preconstruction activities were rated for each project based on the perception by the respondent of how well the project team performed each service. The mean responses for all projects, as well as the mean response per delivery method, are summarized in Table 1. Variance from the sample mean is also given in Table 1. Positive variance shows an improvement in the objective. In other words, a positive variance would show that delivery method is better suited to achieve the preconstruction service goal being analyzed. Because the means were close, a statistically significant variance of means was not obtained at the 95 percent confidence level for all preconstruction services; however, several means did reach a significant level. Means that reached a level of statistical significance at the 95 percent confidence level have been marked with an asterisk.

An analysis of these means and their variations from the total mean gives an indication of how well the different delivery methods are able to perform the preconstruction services. On the left side of Table 1 is a list of the preconstruction services. A comparison of means test was performed between each delivery method. The means are displayed in the table. The variance between the means for each delivery method indicated which delivery method is best suited to complete the related preconstruction service. This is also shown through reported variance. A positive variance indicates a 
The Engineering Project Organization Journal (October 2017) 7, 2

Table 1. Delivery Method Influence on Preconstruction Services Means and Variance

\begin{tabular}{|c|c|c|c|c|c|c|c|c|}
\hline $\begin{array}{c}\text { Preconstruction } \\
\text { Service }\end{array}$ & $\begin{array}{c}\text { Preferred } \\
\text { Delivery } \\
\text { Method } \\
\end{array}$ & $\begin{array}{c}\text { Sample } \\
\text { Mean }\end{array}$ & $\begin{array}{c}\text { DBB } \\
\text { Mean }\end{array}$ & $\begin{array}{c}\text { DBB } \\
\text { Variance }\end{array}$ & $\begin{array}{c}\text { CMAR } \\
\text { Mean }\end{array}$ & $\begin{array}{c}\text { CMAR } \\
\text { Variance }\end{array}$ & $\begin{array}{c}\text { DB } \\
\text { Mean }\end{array}$ & $\begin{array}{c}\text { DB } \\
\text { Variance }\end{array}$ \\
\hline $\begin{array}{l}\text { Identification of } \\
\text { Project Objectives }\end{array}$ & DB & 5.94 & 5.92 & -0.02 & 5.89 & -0.05 & 6.00 & 0.06 \\
\hline $\begin{array}{l}\text { Risk } \\
\text { Identification and } \\
\text { Assessment }\end{array}$ & CMAR* & 5.31 & 5.08 & $-0.23 *$ & 6.00 & $0.69^{*}$ & 5.29 & -0.03 \\
\hline Risk Mitigation & CMAR* & 5.13 & 4.84 & $-0.29 *$ & 6.11 & $0.98^{*}$ & 5.00 & -0.13 \\
\hline $\begin{array}{l}\text { Design } \\
\text { Management }\end{array}$ & $\begin{array}{l}\text { DBB* } \\
\text { CMAR* }\end{array}$ & 5.26 & 5.35 & 0.09 & 5.33 & 0.08 & 5.00 & $-0.26 *$ \\
\hline $\begin{array}{l}\text { Agency } \\
\text { Coordination and } \\
\text { Estimating }\end{array}$ & DBB* & 5.24 & 5.54 & 0.03 & 4.50 & $-0.74 *$ & 5.15 & -0.09 \\
\hline $\begin{array}{l}\text { Constructability/ } \\
\text { Bidability } \\
\text { Analysis }\end{array}$ & CMAR* & 5.37 & 5.36 & -0.01 & 5.89 & $0.52^{*}$ & 5.00 & $-0.37 *$ \\
\hline $\begin{array}{l}\text { Value } \\
\text { Analysis/Enginee } \\
\text { ring }\end{array}$ & CMAR* & 4.98 & 4.81 & -0.17 & 5.67 & $0.67^{*}$ & 4.77 & $-0.21 *$ \\
\hline Bid Packaging & $\begin{array}{l}\mathrm{DBB}^{*} \\
\mathrm{DB}^{*}\end{array}$ & 5.98 & 6.04 & 0.14 & 6.12 & $-0.31 *$ & 5.79 & -0.08 \\
\hline $\begin{array}{l}\text { Schedule } \\
\text { Development }\end{array}$ & CMAR* & 5.34 & 5.20 & -0.11 & 5.67 & $0.71^{*}$ & 5.43 & $-0.27 *$ \\
\hline $\begin{array}{l}\text { Site Logistics } \\
\text { Planning }\end{array}$ & CMAR* & 5.20 & 5.00 & 0.00 & 5.85 & $0.62^{*}$ & 5.21 & $-0.50 *$ \\
\hline $\begin{array}{l}\text { Disruption } \\
\text { Avoidance } \\
\text { Planning }\end{array}$ & CMAR* & 5.21 & 5.33 & 0.07 & 5.09 & $0.52^{*}$ & 5.07 & $-0.48 *$ \\
\hline $\begin{array}{l}\text { SWM owned } \\
\text { Business } \\
\text { Participation }\end{array}$ & DBB & 5.25 & 5.63 & 0.08 & 5.89 & -0.18 & 5.00 & -0.01 \\
\hline $\begin{array}{l}\text { Construction } \\
\text { Phase Sequencing }\end{array}$ & CMAR* & 5.40 & 5.39 & 0.17 & 5.39 & $0.43^{*}$ & 5.42 & $-0.61 *$ \\
\hline $\begin{array}{l}\text { Subcontractor } \\
\text { Prequalification }\end{array}$ & CMAR* & 5.08 & 5.00 & 0.07 & 4.49 & $0.39^{*}$ & 5.29 & $-0.59 *$ \\
\hline $\begin{array}{l}\text { Multiple Bid } \\
\text { Package Planning }\end{array}$ & CMAR* & 6.01 & 6.00 & $-0.49 *$ & 5.94 & $0.89 *$ & 6.08 & $-0.24 *$ \\
\hline $\begin{array}{l}\text { Real-Time Cost } \\
\text { Feedback }\end{array}$ & CMAR* & 5.39 & 5.12 & -0.06 & 5.38 & $0.47^{*}$ & 5.92 & $-0.58 *$ \\
\hline $\begin{array}{l}\text { Building } \\
\text { Information } \\
\text { Modeling }\end{array}$ & CMAR* & 5.24 & 4.88 & $-0.28 *$ & 5.21 & $1.05^{*}$ & 5.92 & $-0.55^{*}$ \\
\hline $\begin{array}{l}\text { Total Cost of } \\
\text { Ownership } \\
\text { Analysis }\end{array}$ & CMAR* & 5.15 & 5.17 & 0.07 & 5.22 & 0.47 * & 5.08 & $-0.33 *$ \\
\hline Cost Estimating & CMAR* & 5.15 & 5.38 & 0.05 & 5.19 & $0.25^{*}$ & 4.67 & $-0.26 *$ \\
\hline $\begin{array}{l}\text { Budget } \\
\text { Management }\end{array}$ & DBB & 5.38 & 5.21 & 0.07 & 5.4 & -0.12 & 5.73 & -0.07 \\
\hline $\begin{array}{l}\text { Stakeholder } \\
\text { Management }\end{array}$ & CMAR* & 5.13 & 5.00 & -0.19 & 5.08 & $0.34^{*}$ & 5.38 & -0.15 \\
\hline
\end{tabular}

$\mathrm{N}=81, *$ denotes statistical significance at the $95 \%$ confidence interval 
effective delivery method to complete the preconstruction service. If the statistical analysis was significant, in other words if the variation between the means of the group were confirmed to be different at the $95 \%$ confidence level, it is marked with an asterisk.

Results showed that alternative project delivery methods (DB and CMAR) consistently outperformed DBB projects. Table 1 gives an indication of a delivery method's ability to influence specific preconstruction services. It shows the delivery method that is better suited to facilitate successful implementation of the preconstruction service. A few notable observations from the table are mentioned here. The project means were close in most cases. This could indicate that the delivery method selected is not the sole predictor of the effectiveness of a preconstruction service. DB and CMAR have a greater ability to mitigate risk more effectively when compared to DBB projects. CMAR showed higher means for value analysis and engineering, and a lower means for subcontractor prequalification. This demonstrates the emphasis on value adding activities within CMAR projects. Building information modeling was also more practical for $\mathrm{DB}$ and CMAR projects, possibly due to the synergy around integration in all these processes. DB projects showed a lower mean for cost estimating, this could indicate a potential for cost growth when using DB. A practitioner could use this information to learn more about the delivery methods that may perform the preconstruction services better (positive deviation from the mean) and those that may not (negative deviation from the mean).

Additional information from the table highlights the structural difference found within the delivery methods. For example, DBB projects were rated higher for their control over 'design management', 'agency coordination', and use of 'small, women, and minority businesses'. Alternative project delivery methods were seen as more beneficial to all other services. Analysis showed that for most preconstruction services identified in the survey, CMAR and DB projects were better equipped to provide those services. This is most likely due to the structure of CMAR and DB projects and the timing of contractor involvement. This is one of the advantages to APDM usage.
The information found in Table 1 is valuable in understanding industry preferences. A practitioner may wish to use this analysis to identify what preconstruction services they wish to implement, and based on the variance given above, as well as the relative importance determined by the practitioner, make a better decision for the best delivery method to select for the project.

\section{Preconstruction Service Costs}

Collected survey responses provided the average costs of preconstruction services for transportation projects; this project data can be used as a guide to estimate preconstruction services for future projects. Data from the surveyed projects showed that the different delivery methods were not equal in terms of the cost of preconstruction services. Table 2 provides the preconstruction service costs as a percentage of total costs for DBB, CMAR, and DB projects. Not surprisingly, CMAR and DB projects had a higher cost percentage for preconstruction services. This information can be used as a benchmark for a transportation preconstruction service costs.

Table 2. Preconstruction Service Costs as a Percentage of Total Costs by Delivery Method

\begin{tabular}{|c|c|}
\hline & $\begin{array}{c}\text { Pre-Construction Service } \\
\text { Costs as a Percent of Total } \\
\text { Costs }\end{array}$ \\
\hline DBB (N=11) & $\mathbf{0 . 2 2 \%}$ \\
\hline CMAR (N=7) & $\mathbf{6 . 1 7 \%}$ \\
\hline $\begin{array}{c}\text { DB (N=9) } \\
\text { All Projects }(\mathrm{N}= \\
27\end{array}$ & $\mathbf{8 . 6 0 \%}$ \\
\hline
\end{tabular}


Figure 1. Most Beneficial Best Practices to Achieve Preconstruction Goals, $N=81$

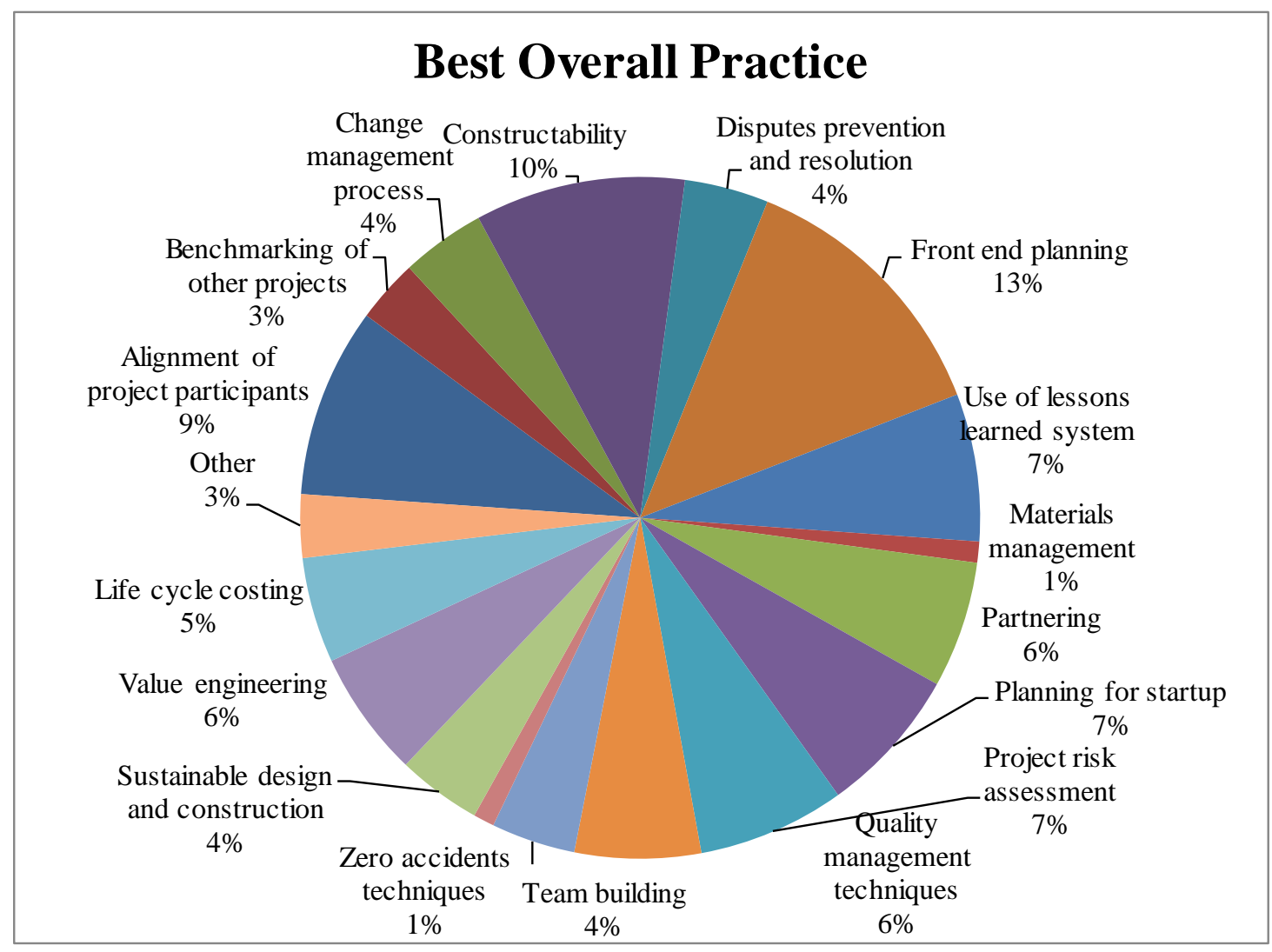

\section{Best Practices in Preconstruction Services}

Preconstruction services should be performed on transportation projects (Gransberg 2016). There are management practices that are better equipped to facilitate in the performance of these services. This study concluded that the various best practices had differing abilities to successfully complete the preconstruction services. The following one sided set of hypotheses was tested:

Null hypothesis $\mathrm{H}_{0}: \mu=\mu_{0}-$ There is not a correlation between individual preconstruction services and industry best practices.

Alternate hypothesis $\mathrm{H}_{\mathrm{A}}$ : $\mu<\mu_{0}-$ Individual preconstruction services have a correlation with industry best practices. Specific best practices will have a greater ability to influence the use of a specific preconstruction service.

Preconstruction services can be more effectively accomplished when proven management practices are implemented. These management practice are often considered "best practices". This research study paired preconstruction services with the practices viewed as the most effective in successful delivery of the specific preconstruction service. The most beneficial best practice to accomplish preconstruction services were ranked. The practices were ranked according to their ability to perform specific preconstruction services and these rankings were also combined to show the best practice for preconstruction in general. Figure 1 shows a pie chart depicting the resulting conclusion to the practices perceived to be the best for overall project success. The best overall practice to accomplish a project's preconstruction service 
Table 3. Best Practices to Achieve Preconstruction Objectives Matrix

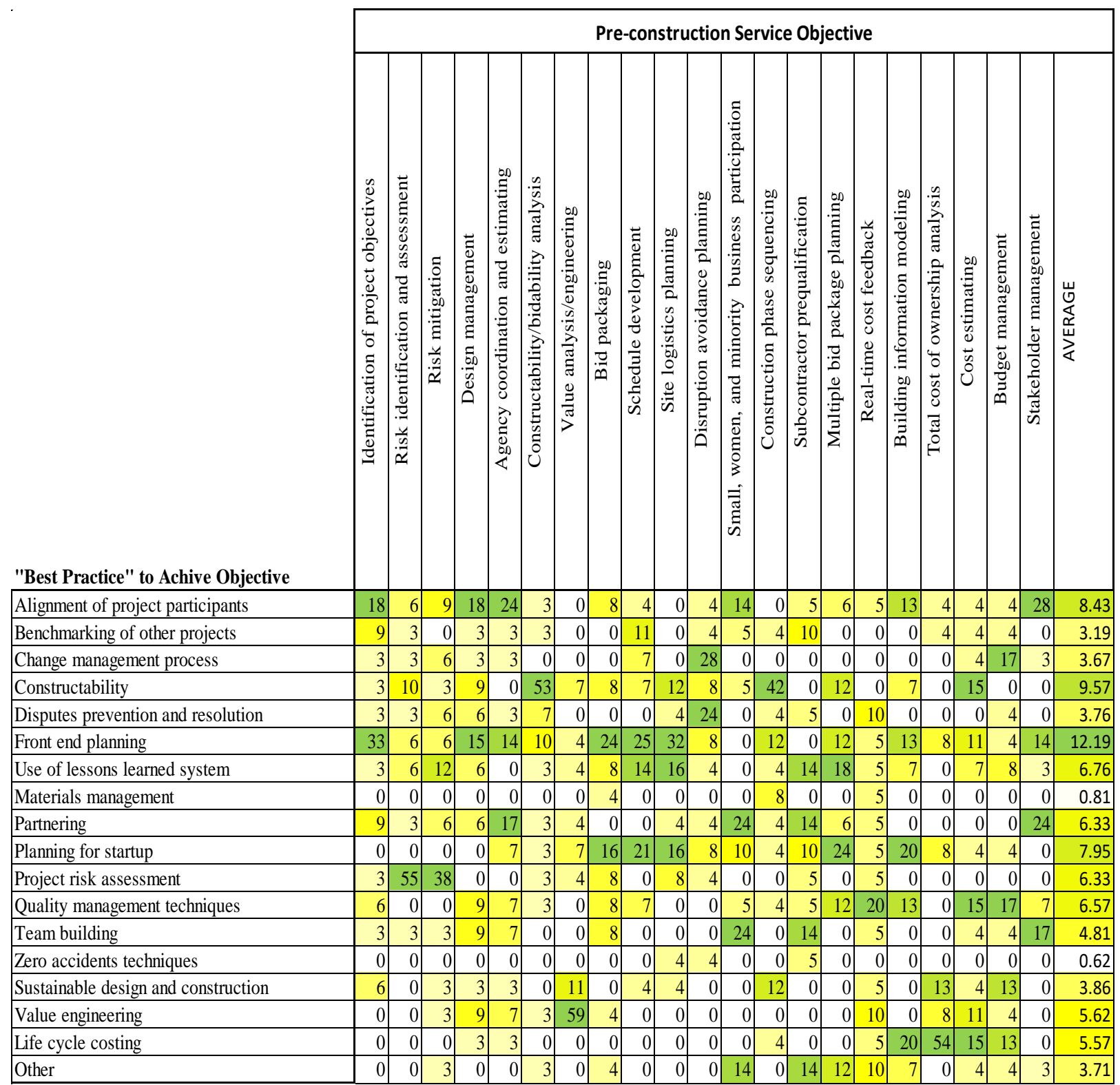

Scale from least to most beneficial

$\mathrm{N}=81, *$ Green indicates a statistical significance at the $95 \%$ confidence interval

goals in general was 'front end planning'. Following closely behind 'front end planning' were 'constructability reviews' and 'alignment of project participants'.
This study found that project teams could use specific practices to successfully accomplish preconstruction services. Some of these practices are considered to be best practices by the industry because they have shown a great ability to affect 
the success of a project. As a project team seeks to perform a specific preconstruction service, they should use the practices that are best fitted for the success of each objective. The matrix provided in Table 3 is a breakdown of the preconstruction services that are often performed by an organization and the practices that should be used to accomplish that service. The numbers in the boxes represent the percentage of responses that felt like the specific practice was the most beneficial to achieve the service objective above. Practices that were found to be most beneficial are highlighted on the table.

The matrix of preconstruction services and best practices gives users information that can be used to make organizational decisions. For example, if one would like to know how to best identify project objectives' for example, the organization would need to focus on the highlighted best practices for that preconstruction service. In this example, the organization would pursue a formal front end planning process, and focus on the alignment of project participants.

\section{Results of Hypotheses Testing}

Analysis performed by the research team showed a correlation between the list of preconstruction services and delivery method. The following hypotheses was confirmed:

Alternate hypothesis $\mathrm{H}_{\mathrm{A}}: \mu \neq \mu_{0}$ - Individual preconstruction services have a correlation with delivery method. Specific delivery methods will have a greater ability to influence the use of a specific preconstruction service. Evidences for the support of this hypothesis were derived from the data from project owners identifying the delivery methods that were better able to accomplish preconstruction goals. Specifically, as seen in Table 1, the delivery method CMAR showed significant abilities to perform pre-construction services.

Furthermore, the research confirmed that preconstruction services correlates to best practices, confirming the hypothesis:
Alternate hypothesis $\mathrm{H}_{\mathrm{A}}: \mu<\mu_{0}-$ Individual preconstruction services have a correlation with industry best practices. Specific best practices will have a greater ability to influence the use of a specific preconstruction service. Table 3 shows the evidences of significant data demonstrating that the use of specific Best Practices should be used to perform preconstruction services. For example, a project wishing to accomplish change management should focus on the best practices of performing quality management and budget management analysis. Highlighted significant findings are provided in the following conclusion section.

\section{Conclusions}

This paper presented a summary of the findings from a recent research effort focused on preconstruction services in the transportation industry. The research contributes to the body of industry knowledge through the analysis of practices performed by organizations that are perceived by industry professionals to have the greatest effect on project control and performance. The findings in this paper can be used by organizations to make better decisions about the type of tools or areas of focus that will give the greatest benefit to the organization. Some notable findings of the research included: Alternative project delivery methods (Design Build and Construction Manager at Risk) are better equipped to perform preconstruction services than the traditional Design Bid Build method; however, DBB projects were rated higher for their control over 'design management', and 'agency coordination'. The best overall practice to accomplish a project's preconstruction service goals was 'front end planning'. Following closely were 'constructability reviews' and 'alignment of project participants'. CMAR and DB projects had a higher percentage of cost for preconstruction services, at 6.17 percent of total construction cost and 8.60 percent of total construction, respectively. DBB projects perform fewer services identified in the preconstruction services phase, and therefore had lower cost associated with these services. Cost for preconstruction services in DBB projects are often recovered in the construction phase. 
The research has contributed to the industry by:

- Providing a list of the most common preconstruction services used in the industry

- An inter/intra-firm collaboration, to determine the best delivery methods for preconstruction services.

- Giving average costs for preconstruction services by delivery method.

- Identifying and providing definitions of practices termed 'best practices' by the industry.

- Compiling a matrix of preconstruction services and the best practices to accomplish these services.

The research into best practices in preconstruction services should be continued to provide a more detailed understanding of the cost associated with preconstruction service (i.e. how to estimate these costs and how to measure the successful implementation of preconstruction services). Future research will continue to improve infrastructure development and governance, inter/intra-firm coordination, and will give critical insight for analyzing and improving coordination within organizations.

\section{References}

CII, Construction Industry Institute. (1994). Pre-Project Planning: Beginning a Project the Right Way. Austin, Texas: University of Texas at Austin

CII, Construction Industry Institute. (2014, March, 19) CII Glossary. Retrieved from https://www.construction-

institute.org/scriptcontent/glossary.cfm?section=kno W

CII, Construction Industry Institute (2014,March, 19) CII Best Practices. Retrieved from https://www.construction-

institute.org/scriptcontent/bp.cfm?section=know

Farnsworth, C., Warr, R., Weidman, J., and Mark Hutchings, D. (2015). "Effects of CM/GC Project Delivery on Managing Process Risk in Transportation Construction." J. Constr. Eng. Manage., 10.1061/(ASCE)CO.1943-7862.0001091, 04015091.

Federal Highway Administration (2006, August, 30). Design Build Effectiveness Study, Final Report to
Congress as Required by TEA-21, Retrieved from http://www.fhwa.dot.gov/reports/designbuild/design build0.htm

Karan, Ebrahim P., Irizarry, Javier., (2015) Extending BIM interoperability to preconstruction operations using geospatial analyses and semantic web services, Automation in Construction, Volume 53, (May 2015), pp. 1-12.

K. Gidado (2004) Enhancing the prime contractor's preconstruction planning. Journal of Construction Research., 5 (01) (2004), pp. 87-106

Gransberg, Douglas D. (2016), POINT OF VIEW: Estimating Preconstruction Costs: Who Cares? Why Bother? TR News, (Issue Number 301), Transportation Research Board., ISSN:0738-6826. Pp37-39

Hayter, Anthony J. (2002) Probability and Statistics for Engineers and Scientists, $2^{\text {nd }}$ edn, Wadsworth Group, Pacific Grove.

Kuhn, Steve. (2007, February) Preconstruction Services: Add value with more than Just Estimating. Construction Business Owner, (Feb 2007 Issue). Retrieved from http://www.constructionbusinessowner.com/topics/a ccounting/accounting-finance/preconstructionservices-add-value-more-just-estimating

NCHRP, National Cooperative Highway Research Program (2016). Estimating Highway Preconstruction Services Costs - Volume 1: Guidebook. Transportation Research Board, NCHRP Report 826.

UDOT, Utah Department of Transportation (2009). Alternative Contracting Process, SEP 14 CMHC Annual Report, Transportation Research Board, retrieved from http://www.trb.org/Main/Blurbs/159712.aspx 